\title{
DIGITAL REJOINDERS: TIME \& PLACE, HITHER \& THITHER, WAR \& PEACE
}

\author{
Mikel Horl (also known as Michael Hall) \\ Teesside University, Institute of Design, Culture and the Arts, \\ School of Arts and Media, Teesside University, Middlesbrough, UK, TS1 3BA \\ Michael.Hall@tees.ac.uk
}

\begin{abstract}
How can communications media aid interdisciplinary and collaborative story-telling? What forms of interaction can be developed to support more effective visual and literal reading? How might the relationship between image and text be changing in the age of the smartphone, the iPad and the Kindle?
\end{abstract}

Communications. Publishing. Illustration. Graphics. Narrative. Collaboration. Interaction. Convergence. Transmedia.

\section{INTRODUCTION}

Visual communicators, authors, publishers and their audiences are now feeling the cultural and economic effects of technological convergence on the transmission and reception of ideas. In January 2011 Amazon.com claimed to be selling more Kindle ebooks than traditional paperbacks in the USA. This suggests a shift in reading habits towards a more blended transmedia experience and a shift in buying habits away from printed publications.

This demonstration is a practice-based exploration of graphic language. It examines the ability of participants to transmit and receive visual information and proposes to develop enhanced pictorial reading experiences. It builds upon my own experience as a graphic designer, author and publisher of artists' books and has grown out of my establishment of the AgB collective in London, cofounded with Pete Nevin in 1994.

\section{MOTIVATION}

How conscious are we of the communications revolutions we are living through? Does the new technology offer opportunities for different, more collective methods of authorship?

\begin{abstract}
At root most creativity is collaborative; it is not usually the product of a lone individual's flash of insight. The web gres us a new way to organise and expand this collaborative activity ${ }^{1}$.
\end{abstract}

If this project is successful it will reveal current and future potential for artist-publishers. It will provide new insight and understanding of the "reading" of visual information. Enhanced collective reading experiences will impact on electronic publishing, educational publishing and curatorial practice.

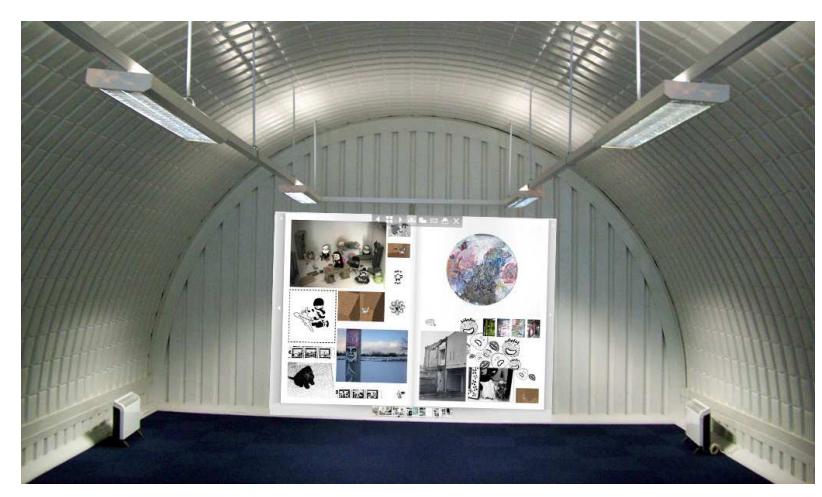

Figure 1: Proposed Installation of Digital Newspaper

\section{APPROACH}

The demonstration features a projected display of digital documents, explaining the themes of the work, the methodologies of origination, the collection and collation of project assets, the editorial process and the use of online services. It is an exercise in both composing and reading graphic language. A visual proposition will be made for the next stage of the project: to install largescale interactive projections of digital newspapers in a gallery environment. Key findings so far will be revealed in the demonstration.

Subsequent work will investigate new forms of publishing and will ask: What consequences and possibilities might there be for artists and authors as independent publishers? What opportunities for co-creation have been presented by technological convergence?

\section{REFERENCES}

Leadbeater, C. (2008) We-Think: Mass Innovation, Not Mass Production. Profile, London. 